\title{
Evaluation of serum D-dimer, fibrinogen, and CA19-9 for postoperative monitoring and survival prediction in resectable pancreatic carcinoma
}

\author{
Junli Cao ${ }^{1}$, Zhanzhao Fu², Liming Gao², Xin Wang ${ }^{3}$, Shaohui Cheng ${ }^{2}$, Xiuchao Wang ${ }^{1}$ and He Ren ${ }^{1 *}$
}

\begin{abstract}
Background: We sought to investigate the efficacy of serum D-dimer, fibrinogen, and CA19-9 for postoperative monitoring and prediction of survival in patients with resectable pancreatic carcinoma (PC).

Methods: One hundred and nineteen patients with resectable PC were enrolled. Serum D-dimer, fibrinogen, and CA19-9 values were analyzed before surgery and at the stages of relapse-free and progression disease.

Results: D-dimer, fibrinogen, and CA19-9 were significantly higher at the active stage of PC than those at the relapse-free stage [1059.2 (1690.1) ng/ml vs $485.18(289.84) \mathrm{ng} / \mathrm{ml},(3.71 \pm 0.83) \mathrm{g} / \mathrm{l} \mathrm{vs}(2.75 \pm 0.52) \mathrm{g} / \mathrm{l}, 207.2(681.8)$ $\mathrm{U} / \mathrm{ml}$ vs $24.5(30) \mathrm{U} / \mathrm{ml}$, respectively, $p<0.01$ ]. Patients with elevated preoperative D-dimer had significantly shorter overall survival $(18.9 \pm 1.9$ months vs $29.2 \pm 2.6$ months, $p<0.01)$ and progression-free survival $(10.6 \pm 1.2$ months vs $20.4 \pm 2.4$ months, $p<0.01)$ than did those with low D-dimer. The correlation between CA19-9 values and survival depended on the threshold value of CA19-9: when the threshold value was $37 \mathrm{U} / \mathrm{ml}$, there was no correlation between CA19-9 and survival; when the threshold value was $253.8 \mathrm{U} / \mathrm{ml}$ (median CA19-9 for the enrolled patients), patients with elevated preoperative CA19-9 had significantly shorter overall survival (19.9 \pm 2.1 months vs $29.0 \pm 2$. 7 months) and progression-free survival (11.5 \pm 1.5 months vs $21.0 \pm 2.6$ months) than did the patients with low CA19-9 $(p<0.01)$; when the threshold value was $1000 \mathrm{U} / \mathrm{ml}$, the overall survival was $15.5 \pm 2.3$ months vs $28.0 \pm 2$. 0 months and the progression-free survival $8.9 \pm 1.9$ months vs $19.1 \pm 1.9$ months $(p<0.01)$. There was no correlation between fibrinogen and overall survival $(25.8 \pm 2.1$ months vs $21.2 \pm 2.9$ months; $p=0.096)$ and progression-free survival (17.8 \pm 2.1 months vs $12.7 \pm 1.7$ months; $p=0.168)$.
\end{abstract}

Conclusions: For postoperative monitoring of patients with resectable PC, D-dimer, fibrinogen, and CA19-9 may be used as markers for monitoring disease relapse, but only preoperative D-dimer could predict survival.

Keywords: Pancreatic adenocarcinoma, Pancreatic cancer, Biomarkers, D-dimer, Fibrinogen, CA19-9, Postoperative monitoring, Survival prediction

\footnotetext{
*Correspondence: herenhr@126.com

'Department of Pancreatic Cancer, Key Laboratory of Cancer Prevention and

Therapy, National Clinical Research Center for Cancer, Tianjin Medical

University Cancer Institute and Hospital, Tianjin 300060, People's Republic of

China

Full list of author information is available at the end of the article
} 


\section{Background}

Pancreatic carcinoma (PC) is a leading cause of cancerrelated mortality, with 5 -year survival less than $8 \%[1,2]$. Despite substantial therapeutic progress, PC remains one of the most aggressive cancers. Radical surgery is the most effective therapy for resectable PC, but postoperative recurrence or metastatic disease are barriers to prolonged survival. For most patients, the disease progresses soon after surgery, and, unfortunately, imaging is not sufficiently sensitive to detect early recurrence or metastasis. Thus, better markers for post-resection disease monitoring are needed and are being investigated [3-7].

Abnormalities in the coagulation/fibrinolytic system, especially plasma D-dimer and fibrinogen, have been identified in cancer patients. D-dimer is a degradation product of crosslinked fibrin and a sign of fibrinolytic hyperfunction in vivo. D-dimer has been reported to be a marker of various cancers [8-10]. Fibrin and fibrinogen are identified as major components of the tumor stroma enveloping tumor cells. Plasma D-dimer values and fibrinogen have been reported to be prognostic factors for PC [11-13], but most of these reports focused on metastatic PC, and the results were conflicting [12, 14]. CA 19-9, or sialyl Lewis-a (sLea), is a glycolipid and an O-linked glycoprotein expressed on the surface of cancer cells. CA19-9 is derived from an aberrant pathway during production of its normal counterpart, disialyl Lewis-a. CA19-9 is widely used as biomarker for PC and can be combined with other markers, despite having several limitations [3-7]. So, we investigated whether serum D-dimer, fibrinogen, and CA19-9 are reliable markers for postoperative monitoring and prediction of patient survival for resectable PC.

\section{Methods}

\section{Patients}

Subjects $(N=119)$ were included who met the following criteria: (1) histological confirmation of the diagnosis; (2) tumor resectability, confirmed intraoperatively and by histopathological examinations; (3) radical surgery performed; (4) plasma D-dimer, fibrinogen, and CA19-9 values were measured before surgery (samples taken within 7 days before surgery) and regularly after surgery (most patients were followed every 1 month in the first year and then every 3 months but some had shorter or longer follow-ups); (5) The subjects also had adequate clinical information for survival analysis in patient records and death that was tumor-related (Table 1). Patients with apparent inflammatory diseases, a history of thrombosis or treatment with drugs that might influence the coagulation/fibrinolytic system, or severe jaundice that might influence CA19-9 were excluded. Also, 30 samples from healthy individuals and 40 samples from

Table 1 Relationships between clinicopathological characteristics and preoperative plasma D-dimer, fibrinogen, and CA19-9 values in 119 PC patients

\begin{tabular}{|c|c|c|c|c|c|c|c|c|c|c|}
\hline \multirow[t]{2}{*}{ Variable } & \multirow{2}{*}{$\begin{array}{l}\text { Total } \\
(n)\end{array}$} & \multicolumn{3}{|c|}{ D-dimer (ng/ml) } & \multicolumn{3}{|c|}{ Fibrinogen (g/l) } & \multicolumn{3}{|c|}{ CA19-9 (U/ml) } \\
\hline & & $\leq 500^{a}$ & $>500$ & $p$ value & $\leq 4^{a}$ & $>4$ & $p$ value & $\leq 37^{a}$ & $>37$ & $p$ value \\
\hline$\overline{S e x}$ & 119 & & & 0.809 & & & 0.709 & & & 0.323 \\
\hline Male & 70 & 37 & 33 & & 48 & 22 & & 15 & 55 & \\
\hline Female & 49 & 27 & 22 & & 32 & 17 & & 7 & 42 & \\
\hline Age (years) & 119 & & & 0.580 & & & 0.352 & & & 0.071 \\
\hline$\leq 60$ & 66 & 34 & 32 & & 42 & 24 & & 16 & 50 & \\
\hline$>60$ & 53 & 30 & 23 & & 38 & 15 & & 6 & 47 & \\
\hline Tumor size & 119 & & & 0.514 & & & 0.926 & & & 0.718 \\
\hline$\leq 4 \mathrm{~cm}$ & 94 & 52 & 42 & & 63 & 31 & & 18 & 76 & \\
\hline$>4 \mathrm{~cm}$ & 25 & 12 & 13 & & 17 & 8 & & 4 & 21 & \\
\hline TNM & 119 & & & 0.116 & & & 0.512 & & & 0.564 \\
\hline । & 32 & 21 & 11 & & 23 & 9 & & 7 & 25 & \\
\hline$\|$ & 87 & 43 & 44 & & 57 & 30 & & 15 & 72 & \\
\hline Lymphatic metastasis & 119 & & & 0.678 & & & 0.674 & & & 0.036 \\
\hline Negative & 95 & 52 & 43 & & 63 & 32 & & 14 & 81 & \\
\hline Positive & 24 & 12 & 12 & & 17 & 7 & & 8 & 16 & \\
\hline Tumor differentiation & 119 & & & 0.266 & & & 0.256 & & & 0.842 \\
\hline 1-2 grade & 90 & 51 & 39 & & 63 & 27 & & 17 & 73 & \\
\hline 3 grade & 29 & 13 & 16 & & 17 & 12 & & 5 & 24 & \\
\hline
\end{tabular}

${ }^{\mathrm{a}}$ Normal upper limit 
Table 2 Plasma D-dimer, fibrinogen, and CA19-9 at various stages of PC

\begin{tabular}{|c|c|c|c|c|}
\hline Serum test & Relapse-free stage & Progressive disease & $\mathrm{z} / \mathrm{t}$ & $p$ \\
\hline D-dimer (ng/ml) & $485.18(289.84)$ & $1059.2(1690.1)$ & -7.490 & $<0.001$ \\
\hline Fibrinogen (g/l) & $2.75 \pm 0.52$ & $3.71 \pm 0.83$ & -10.228 & $<0.001$ \\
\hline CA19-9 (U/ml) & $24.5(30)$ & $207.2(681.8)$ & -8.669 & $<0.001$ \\
\hline
\end{tabular}

Eight patients were excluded because they also had deep vein thrombosis, and two were excluded for serious infections. Samples from patients considered at relapse-free stage were extracted 1.8 months (median) before progressive. Samples from patients considered progressive disease were extracted 5 days (median) before progressive disease

patients with serous pancreatic cystadenoma were collected as controls. The "relapse-free stage" was defined as no new lesions found by CT or MRI. "Progressive disease" was defined as new lesions found by CT or MRI or biopsy.

\section{Biomarker measurements}

Plasma D-dimer was measured with Innovance D-dimer immunoassays with the Vidas D-dimer kit (VIDAS DD, France); fibrinogen was measured by immunoturbidimetry. CA19-9 was measured with a chemiluminescent immunoassay. All blood samples were collected in the early morning, fasting. Normal reference values for plasma D-dimer, fibrinogen, and CA19-9 were 0$500 \mathrm{ng} / \mathrm{ml}, 2-4.0 \mathrm{~g} / \mathrm{l}$, and $0-37 \mathrm{U} / \mathrm{ml}$, respectively.

\section{Statistical analysis}

Measurements were reported as means \pm SEM or as medians (interquartile range), depending on the distribution of data. An independent sample Student's $t$ test and a nonparametric test were used to make comparisons between groups. A Chi-squared test was used to evaluate the association between clinicopathological measurements and D- dimer, fibrinogen, or CA19-9 values. Survival outcomes were analyzed with a Kaplan-Meier method, and comparisons between groups were made using a log-rank test. To establish a COX regression model analysis of independent factors for survival of patients with $\mathrm{PC}$, statistical analyses were performed with SPSS17.0 software ( $p$ values $\leq 0.05$ were considered statistically significant).

\section{Results}

Preoperative plasma D-dimer, fibrinogen, and CA19-9 values in PC patients

The median (interquartile range) of preoperative plasma D-dimer and CA19-9 were $450.0(688.3) \mathrm{ng} / \mathrm{ml}$ and 253.8 (1188) U/ml, respectively. Fibrinogen was $(3.59 \pm 0.84) \mathrm{g} / \mathrm{l}$. Plasma D-dimer values were above $500 \mathrm{ng} / \mathrm{ml}$ in 55 (46.2\%) patients; $32.8 \%$ of patients had hyperfibrinogemia; and $100(84.0 \%)$ had higher than normal CA19-9. In healthy controls, the median (interquartile range) of plasma D-dimer and CA19-9 were 109.89 (124.09) ng/ml and $12.27(10.14) \mathrm{U} / \mathrm{ml}$, respectively, and fibrinogen was $(2.49 \pm 0.37) \mathrm{g} / \mathrm{l}$. For patients with serous pancreatic cystadenoma, the median (interquartile range) of plasma Ddimer and CA19-9 were $218.86(227.27) \mathrm{ng} / \mathrm{ml}$ and

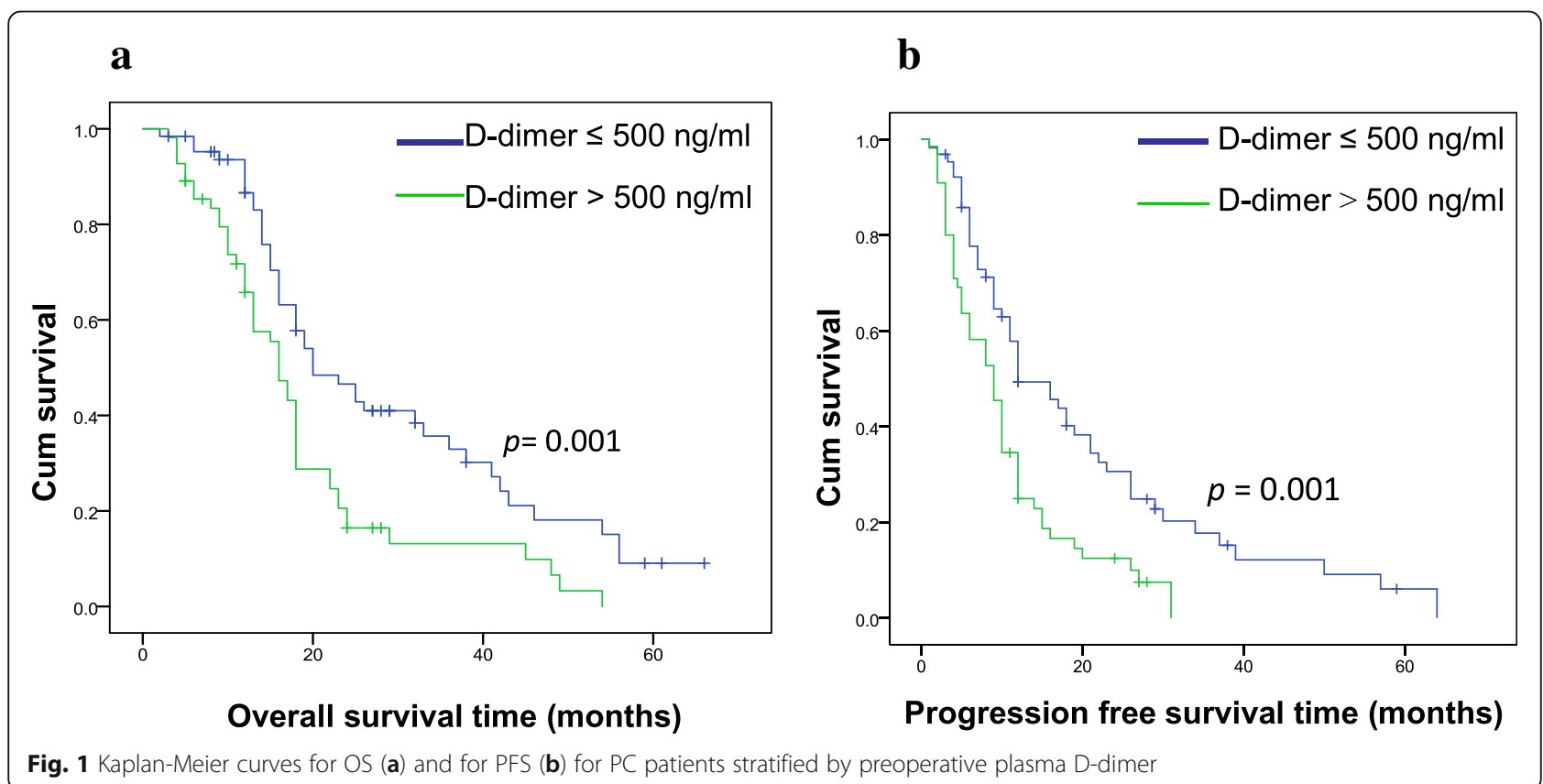




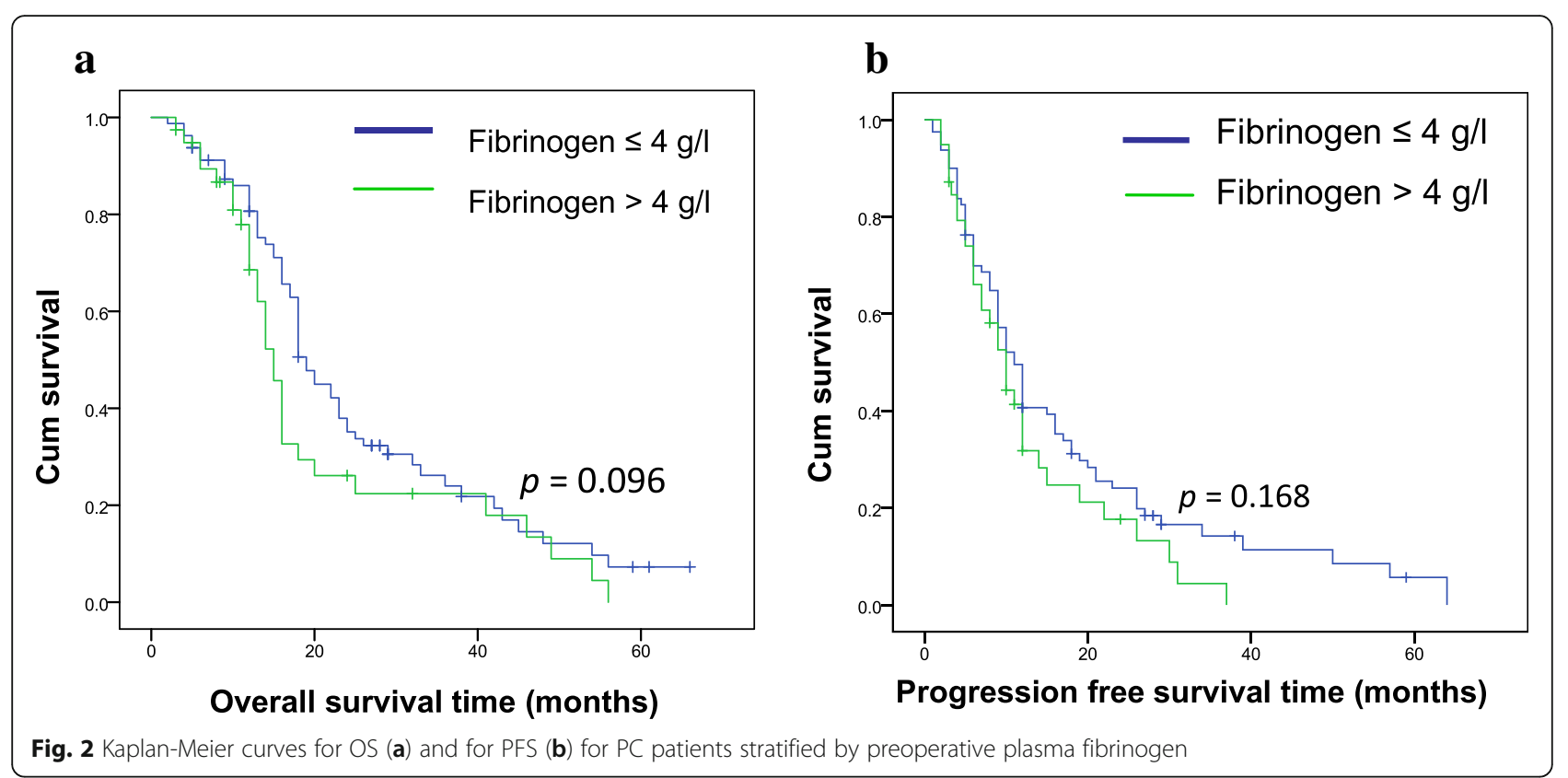

28.73(28.9) $\mathrm{U} / \mathrm{ml}$, respectively, and fibrinogen was $(2.78 \pm$ $0.50) \mathrm{g} / \mathrm{l}$. Three biomarkers were higher in patients with serous pancreatic cystadenoma than healthy controls, but all were within the normal range. A Chi-squared test showed that CA19-9 was a more sensitive marker for PC than D-dimer or fibrinogen $\left(\chi^{2}=37.46\right.$ and 64.36 , respectively, $p<0.01)$. There were no significant correlations between clinicopathological characteristics (sex, age, tumor size, TNM stage, lymphatic metastasis, tumor differentiation) and plasma D-dimer or fibrinogen values $(p>0.05)$. However, among the subset of patients who had lymphatic metastases, CA19-9 values were significantly higher than in those who did not have metastases $(p=0.036)$.

\section{Postoperative plasma D-dimer, fibrinogen, and CA19-9} values as biomarkers for postoperative monitoring of PC As shown in Table 2, plasma D-dimer, fibrinogen, and CA19-9 increased significantly when disease was progressive $(p<0.001)$. Sensitivities of D-dimer, fibrinogen, and CA19-9 were $82.6,40.4$, and $79.8 \%$, respectively.

\section{Preoperative plasma D-dimer as a biomarker for survival prediction}

Patients were followed from 3 to 66 months postoperatively. Overall survival (OS) was defined as the interval between the date of surgery and either the time of death due to PC or the last follow-up. Progression free survival (PFS) was defined as the interval between the date of surgery and either the time of disease progression or the last follow-up. Disease progression was confirmed by imaging examination or pathological examination.

Figure 1 illustrates that patients with elevated preoperative D-dimer values ( $>500 \mathrm{ng} / \mathrm{ml}$ ) had significantly shorter OS $(18.9 \pm 1.9$ months vs $29.2 \pm 2$. 6 months; $p=$ $0.001)$ and PFS $(10.6 \pm 1.2$ months vs $20.4 \pm 2.4$ months; $p=0.001)$ than did those with lower $(\leq 500 \mathrm{ng} / \mathrm{ml}) \mathrm{D}$ dimer. In contrast, as illustrated in Fig. 2, there was no correlation between preoperative fibrinogen and OS (25.8 \pm 2.1 months vs $21.2 \pm 2.9$ months, $p=0.096)$, and PFS $(17.8 \pm 2.1$ months vs $12.7 \pm 1.7$ months, $p=0.168)$.

D-dimer was abnormally high in 48 patients, and CA19-9 was elevated in 38 patients who were considered at relapse-free stage according to imaging. Statistical analysis showed that abnormally higher D-dimer was associated with shorter OS (19.2 \pm 2.5 months vs $27.2 \pm 2.4$ months, $p=0.017$ ), but there was no difference between abnormal and normal CA19-9 (21.5 \pm 2.9 months vs $25.1 \pm 2.3$ months, $p=0.265$ ). Elevated Ddimer and CA19-9 values were associated with shorter PFS $(13.2 \pm 2.3$ months vs $17.7 \pm 2.3$ months and $12.4 \pm$

Table 3 Comparisons of survival and preoperative CA19-9 in PC patients

\begin{tabular}{|c|c|c|c|c|c|c|}
\hline \multirow[t]{2}{*}{ Variable } & \multicolumn{6}{|c|}{ CA19-9 (U/ml) } \\
\hline & $\leq 37$ & $>37$ & $\leq 253.8$ & $>253.8$ & $\leq 1000$ & $>1000$ \\
\hline OS (m) & $27.8 \pm 3.9$ & $23.8 \pm 1.8$ & $29.0 \pm 2.7$ & $19.9 \pm 2.1$ & $28.0 \pm 2.0$ & $15.5 \pm 2.3$ \\
\hline PFS (m) & $18.8 \pm 2.9$ & $15.1 \pm 1.6$ & $21.0 \pm 2.6$ & $11.5 \pm 1.5$ & $19.1 \pm 1.9$ & $8.9 \pm 1.9$ \\
\hline
\end{tabular}




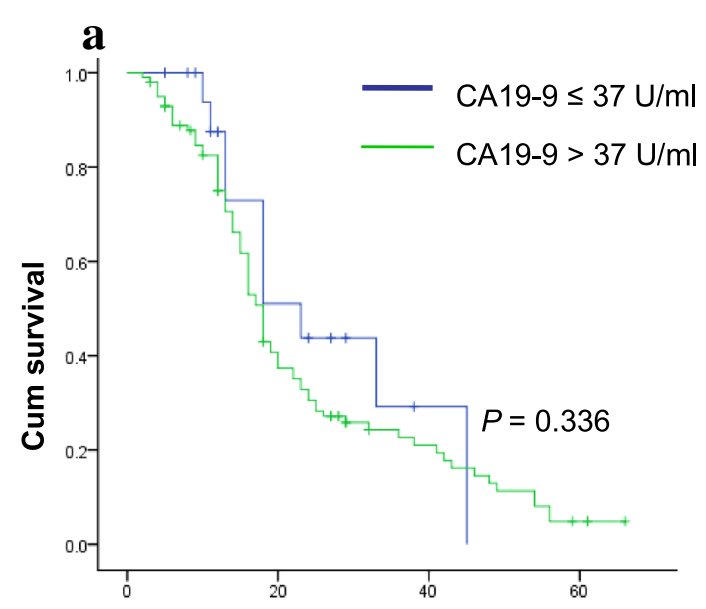

Overall survival time (months)

C

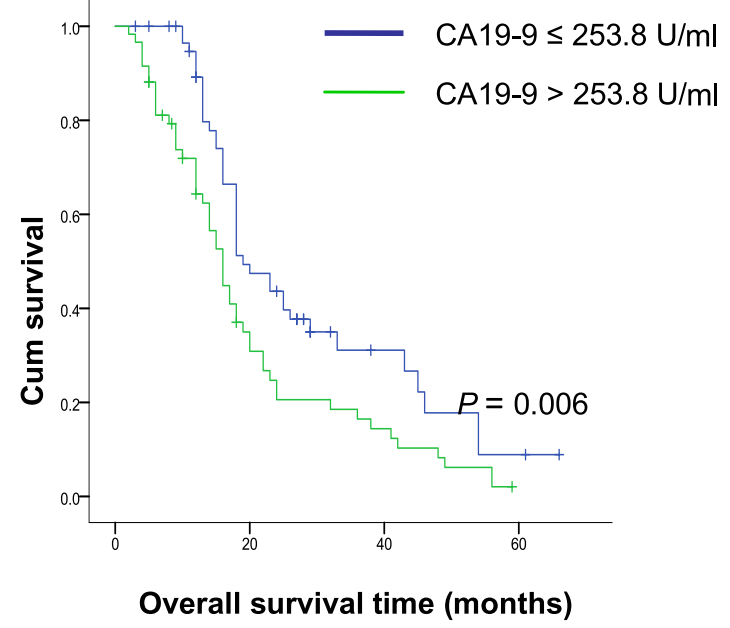

e

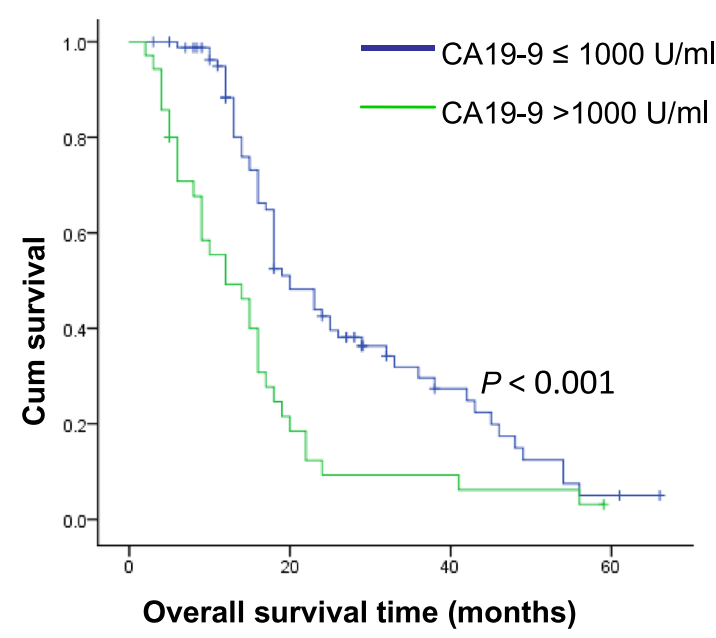

b

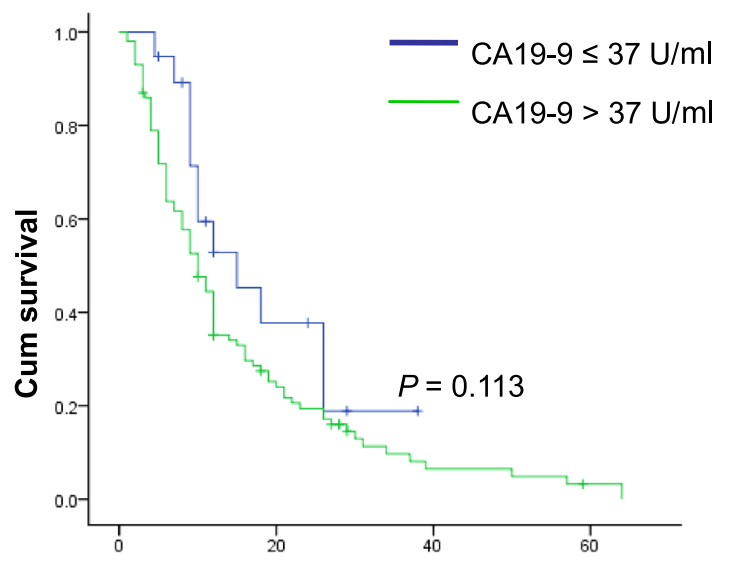

Progression free survival time (months)

d

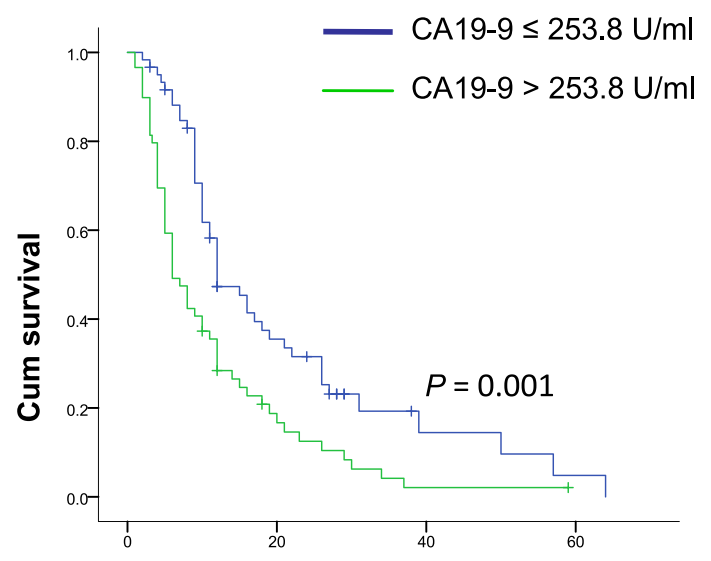

Progression free survival time (months)

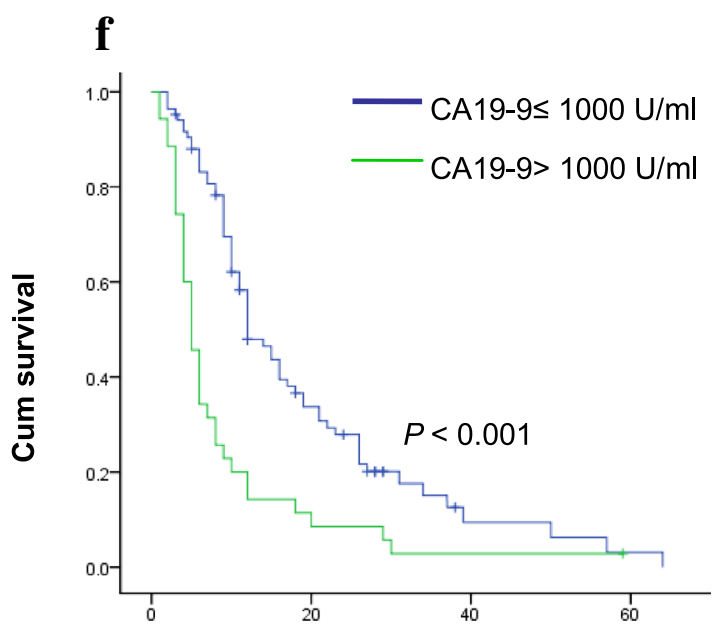

Progression free survival time (months)

Fig. 3 Kaplan-Meier curves for OS and PFS for PC patients stratified by preoperative CA19-9. a, b Threshold value of $37 \mathrm{U} / \mathrm{ml}$. c, d Threshold value of $253.8 \mathrm{U} / \mathrm{ml}$. e, f Threshold value of $1000 \mathrm{U} / \mathrm{ml}$ 
2.3 months vs $17.8 \pm 2.3$ months, $p=0.065$ and 0.074 , respectively), but these differences were not significant.

Table 3 and Fig. 3 illustrate relationships between preoperative CA19-9 values and survival, and OS and PFS depended on the CA19-9 threshold value. When the threshold value was $37 \mathrm{U} / \mathrm{ml}$, it did not affect the survival. If the threshold value was 253.8 or $1000 \mathrm{U} / \mathrm{ml}$, patient survival was negatively correlated with CA19-9 values. Tables 4 and 5 show that preoperative D-dimer was an independent risk factor for PFS for patients and that preoperative D-dimer and CA19-9 were independent factors affecting OS.

\section{Discussion}

We investigated whether serum D-dimer, fibrinogen, and CA19-9 are reliable biomarkers for postoperative monitoring and prediction of survival in patients with resectable $\mathrm{PC}$. We found that plasma D-dimer values could predict OS and PFS of PC and CA19-9 correlated with OS and PFS but only when the threshold value exceeded normal values and there was no correlation between fibrinogen and OS or PFS. Also, D-dimer, fibrinogen, and CA19-9 were significantly higher with active disease than when the cancer is at a relapse-free stage. D-dimer and CA19-9 were abnormally high in some patients who were considered to be at a relapse-free stage according to CT or MRI scan. Furthermore, patients with abnormally high D-dimer had shorter OS than those with normal D-dimer. Likely, rising D-dimer and CA19-9 values may predict early postoperative tumor recurrence or progression of $\mathrm{PC}$, but more work is required to confirm this.

Some studies have indicated that the coagulation/fibrinolytic system is activated in cancer patients and it may contribute to cancer progression $[15,16]$. Thus, tumor-related degradation products of the coagulation and fibrinolytic system have been proposed to predict tumor load and prognosis $[15,16]$. Plasma D-dimer is a procoagulation factor that may reflect the presence of micrometastases or circulating tumor cells, which may be responsible for tumor recurrence [17]. Hyperfibrinogenemia can enhance the sustained adherence of tumor cell emboli in the vasculature of target organs, helping to establish metastases [18]. Because of a likely involvement of the coagulation/fibrinolytic system in cancer, we studied whether D-dimer and fibrinogen are useful biomarkers for postoperative monitoring and survival

Table 4 COX regression model analysis of PFS for PC patients

\begin{tabular}{lllllc}
\hline & $\mathrm{B}$ & $\mathrm{SE}$ & Wald & Sig. & $\operatorname{Exp}(\mathrm{B})$ \\
\hline Preoperative D-dimer & 0.000 & 0.000 & 12.780 & 0.000 & 1.000 \\
Preoperative fibrinogen & 0.097 & 0.145 & 0.443 & 0.506 & 1.102 \\
Preoperative CA19-9 & 0.000 & 0.000 & 2.189 & 0.139 & 1.000 \\
\hline
\end{tabular}

Table 5 COX regression model analysis of OS for PC patients

\begin{tabular}{lllllc}
\hline & $\mathrm{B}$ & $\mathrm{SE}$ & Wald & Sig. & Exp (B) \\
\hline Preoperative D-dimer & 0.000 & 0.000 & 6.250 & 0.012 & 1.000 \\
Preoperative fibrinogen & 0.185 & 0.162 & 1.298 & 0.255 & 1.203 \\
Preoperative CA19-9 & 0.000 & 0.000 & 5.071 & 0.024 & 1.000 \\
\hline
\end{tabular}

prediction for resectable PC. We found that although plasma D-dimer and fibrinogen were higher when disease was active, only D-dimer values were correlated with OS and PFS.

Our observations on the coagulation/fibrinolytic system in PC can be compared with other reports, although this is difficult because of differences in clinical circumstances and study objectives. Stender's group [19] reported that D-dimer is prognostic for non-resectability of PC, and Durcynski et al. [20, 21] reported that high D-dimer values may predict unresectability even when imaging studies predicted resectability. Liu et al. [12] indicated that plasma D-dimer and platelet counts and treatment response are independent prognostic factors for OS which was consistent with our results. Tas' group [14] reported that serum D-dimer was elevated in patients with metastatic pancreatic adenocarcinoma. Sun et al. [22] found that pretreatment plasma D-dimer values were potentially prognostic in pancreatic adenocarcinoma even in the absence of venous thromboembolism. Most current study objectives are focused on unresectable or metastatic pancreatic adenocarcinoma which differ from our objectives. Thus, D-dimer measurements may have clinical utility for managing PC.

Studies of fibrinogen in PC, such as those by Qi and colleagues [13] suggest that hyperfibrinogen with associated systemic inflammatory response was predictive of poor prognosis in advanced PC. Wang's group [23] reported that pretreatment platelet and fibrinogen correlated with tumor progression, metastases, and OS for patients with PC. Guo's group [11] reported that elevated fibrinogen may predict metastases. Our results appear to contradict these, which may be explained by patients at different disease stages. Thus, the status of fibrinogen with respect to clinical assessment of PC is uncertain.

Serum CA19-9 has been used as a marker for diagnosis and therapeutic monitoring of $\mathrm{PC}$, but few studies have investigated the value of CA19-9 for predicting survival in resectable PC. We found that serum CA19-9 could not predict survival in PC when the threshold value was set at $37 \mathrm{U} / \mathrm{ml}$, which conflicts with the conclusion from Ballehaninna's group [24], but this warrants study because we included 19 patients with CA19-9 $\leq$ $37 \mathrm{U} / \mathrm{ml}$. When we analyzed survival using CA19-9 values of $>1000$ or $253.8 \mathrm{U} / \mathrm{ml}$ (median CA19-9 of all subjects), the patients had significantly shorter OS and 
PFS. Thus, it appears that if an appropriate threshold value of CA19-9 is used, CA19-9 can be a predictor of survival in resectable PC. This opinion is corroborated by work by Qi's group [13], who reported that CA19-9 $\geq$ $1000 \mathrm{U} / \mathrm{ml}$ were prognostic for poor OS. Matsumoto et al. [25] reported that preoperative CA19-9 $\geq 300 \mathrm{U} / \mathrm{ml}$ values are independent risk factors for early recurrence of PC. In other work in PC, early decreases in CA19-9 reportedly predicted favorable outcomes in advanced disease [26]. In this study, we found that positive expression of CA19-9 was greater than that of D-dimer and fibrinogen. This finding may also reflect the fact that activation of the coagulation/fibrinolytic system mostly occurs in advanced disease, and most of our patients had early-stage disease. In addition, most of our patients had small tumors and a low rate of lymph node metastases.

Our study is limited as are other studies to identify cancer biomarkers. Scara's group [27] reported that although many putative biomarkers for PC have been proposed, most lack validation and none has been shown to possess the requisite sensitivity and specificity to be introduced into clinical use.

\section{Conclusions}

For postoperative monitoring of patients with resectable PC, fibrinogen and CA19-9 may be used as markers, but only preoperative $\mathrm{D}$-dimer predicts survival. This information may be useful for the care and counseling of patients who undergo surgery for pancreatic adenocarcinoma.

\section{Abbreviations}

OS: Overall survival; PC: Pancreatic carcinoma; PFS: Progression free survival

\section{Acknowledgements}

Not applicable.

\section{Funding}

The Program of Science and Technology Foundation of Qinhuangdao (Grant 201401A158).

\section{Availability of data and materials}

Not applicable.

\section{Authors' contributions}

HR and JC contributed to the study conceptualization and design. JC, SC, and XW contributed to the data acquisition. ZF and LG contributed to the data analysis and interpretation. JC contributed to the manuscript drafting. $\mathrm{HR}$ contributed to the manuscript revision. XW contributed to the statistical analysis. HR contributed to the study supervision. All authors read and approved the final manuscript.

\section{Competing interests}

The authors declare that they have no competing interests.

\section{Ethics approval and consent to participate}

This study was approved by the Institutional Review Board of the First Hospital of Qinhuangdao and the Tumor Hospital Affiliated with Tianjin Medical University, the study site. All patients provided written informed consent for the collection and publication of their medical information at their first hospital visit.

\section{Author details}

'Department of Pancreatic Cancer, Key Laboratory of Cancer Prevention and Therapy, National Clinical Research Center for Cancer, Tianjin Medical University Cancer Institute and Hospital, Tianjin 300060, People's Republic of China. ${ }^{2}$ Department of Oncology, First Hospital of Qinhuangdao, Hebei 066000, People's Republic of China. ${ }^{3}$ Department of Intensive Medicine Traditional Chinese Medicine Hospital of Qinhuangdao, Hebei 066000, People's Republic of China.

Received: 1 September 2016 Accepted: 18 January 2017

Published online: 20 February 2017

\section{References}

1. Siegel RL, Miller KD, Jemal A. Cancer statistics, 2016. CA Cancer J Clin. 2016; 66:7-30.

2. Vincent A, Herman J, Schulick R, Hruban RH, Goggins M. Pancreatic cancer. Lancet. 2011;378:607-20.

3. Herreros-Villanueva M, Bujanda L. Non-invasive biomarkers in pancreatic cancer diagnosis: what we need versus what we have. Ann Transl Med. 2016:4:134.

4. Guo J, Xie K, Zheng S. Molecular biomarkers of pancreatic intraepithelial neoplasia and their implications in early diagnosis and therapeutic intervention of pancreatic cancer. Int J Biol Sci. 2016;12:292-301.

5. Viterbo D, Gausman V, Gonda T. Diagnostic and therapeutic biomarkers in pancreaticobiliary malignancy. World J Gastrointest Endosc. 2016;8:128-42.

6. Karandish F, Mallik S. Biomarkers and targeted therapy in pancreatic cancer. Biomark Cancer. 2016;8:27-35.

7. Le N, Sund M, Vinci A. Prognostic and predictive markers in pancreatic adenocarcinoma. Dig Liver Dis. 2016;48:223-30.

8. Luo YL, Chi PD, Zheng X, Zhang L, Wang SP, Chen H. Preoperative D-dimers as an independent prognostic marker in cervical carcinoma. Tumour Biol. 2015;36:8903-11.

9. Ma X, Li Y, Zhang J, Huang J, Liu L. Prognostic role of D-dimer in patients with lung cancer: a meta-analysis. Tumor Biol. 2014;35:2103-9.

10. Chen F, Wang MJ, Li J, Yan CE, Han XH, Wu ZY, et al. Plasma D-dimer value as a predictor of malignant lymph node involvement in operable non-small cell lung cancer. Tumour Biol. 2015;36:9201-7.

11. Guo Q, Zhang B, Dong X, Xie Q, Guo E, Huang H, et al. Elevated levels of plasma fibrinogen in patients with pancreatic cancer: possible role of a distant metastasis predictor. Pancreas. 2009;38:e75-9.

12. Liu P, Zhu Y, Liu L. Elevated pretreatment plasma D-dimer levels and platelet counts predict poor prognosis in pancreatic adenocarcinoma. Onco Targets Ther. 2015:8:1335-40.

13. Qi Q, Geng Y, Sun M, Chen H, Wang P, Chen Z. Hyperfibrinogen is associated with the systemic inflammatory response and predicts poor prognosis in advanced pancreatic cancer. Pancreas. 2015;44:977-82.

14. Tas F, Karabulut S, Bilgin E, Kilıc L, Ciftci R, Duranyildiz D. Clinical significance of coagulation assays in metastatic pancreatic adenocarcinoma. J Gastrointest Cancer. 2013:44:404-9.

15. Palumbo JS, Talmage KE, Massari JV, La Jeunesse CM, Flick MJ, Kombrinck $\mathrm{KW}$, et al. Platelets and fibrin (ogen) increase metastatic potential by impeding natural killer cell-mediated elimination of tumor cells. Blood. 2005; 105:178-85.

16. Thaler J, Ay C, Mackman N, Bertina RM, Kaider A, Marosi C, et al. Microparticle-associated tissue factor activity, venous thromboembolism and mortality in pancreatic, gastric, colorectal and brain cancer patients. J Thromb Haemost. 2012;10:1363-70.

17. Fukumoto K, Taniguchi T, Usami N, Kawaguchi K, Fukui T, Ishiguro F, et al. The preoperative plasma D-dimer level is an independent prognostic factor in patients with completely resected non-small cell lung cancer. Surg Today. 2015:45:63-7.

18. Palumbo JS, Kombrinck KW, Drew AF, Grimes TS, Kiser JH, Degen JL, et al. Fibrinogen is an important determinant of the metastatic potential of circulating tumor cells. Blood. 2000;96:3302-9. 
19. Stender MT, Larsen AC, Sall M, Thorlacius-Ussing O. D-dimer predicts prognosis and non-resectability in patients with pancreatic cancer: a prospective cohort study. Blood Coagul Fibrinolysis. 2016;27:597-601.

20. Durczynski A, Kumor A, Hogendorf P, Szymanski D, Grzelak P, Strzelczyk J. Preoperative high level of D-dimers predicts unresectability of pancreatic head cancer. World J Gastroenterol. 2014;20:13167-71.

21. Durczynski A, Kumor A, Hogendorf P, Szymanski D, Poznanska G, Grzelak P, et al. D-dimers revisited: a new marker of pancreatic cancer. Am J Clin Oncol. 2014;37:642.

22. Sun W, Ren H, Gao CT, Ma WD, Luo L, Liu Y, et al. Clinical and prognostic significance of coagulation assays in pancreatic cancer patients with absence of venous thromboembolism. Am J Clin Oncol. 2015;38:550-6.

23. Wang H, Gao J, Bai M, Liu R, Li H, Deng T, et al. The pretreatment platelet and plasma fibrinogen level correlate with tumor progression and metastasis in patients with pancreatic cancer. Platelets. 2014;25(5):382-7.

24. Ballehaninna UK, Chamberlain RS. The clinical utility of serum CA 19-9 in the diagnosis, prognosis and management of pancreatic adenocarcinoma: an evidence based appraisal. J Gastrointest Oncol. 2012;3:105-19.

25. Matsumoto I, Murakami Y, Shinzeki M, Asari S, Goto T, Tani M, et al. Proposed preoperative risk factors for early recurrence in patients with resectable pancreatic ductal adenocarcinoma after surgical resection: a multi-center retrospective study. Pancreatology. 2015;15:674-80.

26. Chung KH, Ryu JK, Lee BS, Jang DK, Lee SH, Kim YT. Early decrement of serum carbohydrate antigen 19-9 predicts favorable outcome in advanced pancreatic cancer. J Gastroenterol Hepatol. 2016;31:506-12.

27. Scarà S, Bottoni P. Scatena R. CA 19-9: biochemical and clinical aspects. Adv Exp Med Biol. 2015;867:247-60.

\section{Submit your next manuscript to BioMed Central and we will help you at every step:}

- We accept pre-submission inquiries

- Our selector tool helps you to find the most relevant journal

- We provide round the clock customer support

- Convenient online submission

- Thorough peer review

- Inclusion in PubMed and all major indexing services

- Maximum visibility for your research

Submit your manuscript at www.biomedcentral.com/submit

) Biomed Central 